\title{
Letter to the Editor from Baptist Health South Florida Chief Well-Being Officer
}

\author{
Ana M. Viamonte Ros, MD, MPH
}

Since I left my position as the Florida State Surgeon General in 2011, I have been a board member of the Professional Resource Network (PRN). My work at PRN has included assisting healthcare professionals with resources such as mental health support, addiction treatment, behavioral issues as well as alternatives to official disciplinary action. The work done at PRN truly exposed me to the severity of burnout and moral injury affecting our healthcare workforce. I have made it my goal to educate myself on drivers of burnout, prominence of burnout in our workforce, and what we can do as an organization to reduce burnout and its mental health sequelae.

In 2019, before the pandemic, I was asked to chair the Medical Staff Well-Being Committee to address burnout amongst our medical staff. Shortly thereafter, COVID-19 would test our workforce beyond anything we could have imagined. The entire workforce was asked to serve under tremendous pressure. Our medical staff, nurses, clinical partners, respiratory therapists, environmental staff and others proudly showed up and served despite fears for their own safety and that of their families'. The impact that COVID-19 has had, and will continue to have, on the mental health of our healthcare workforce and the general population is significant. More people are leaving direct patient care roles and there is an increase in the use of mental health services. One positive consequence of COVID-19 has been the recognition that most of us need help sometimes and seeking help does not equate to weakness.

Alongside a great team, we have conducted research, had countless conversations with subject matter experts, and connected with healthcare organizations recognized for their pioneering and successful well-being programs. We developed a robust system-wide well-being program modeled after best evidenced-based practices. Beginning with the medical staff, we have developed programming delivered by experts on topics such as mental health first aid and educational individual and group sessions to help develop effective coping strategies, provide a safe space to discuss workplace challenges, improve our processes and workflows, and decrease the stigma of accessing health resources. Many of our entities and departments are providing different well-being resources. We have developed a newsletter as well as a page on Pineapple Connect to help keep everyone informed about both internal and external resources. I am thankful for the support I have received from our executive leadership team, human resources, community health, pastoral care, and the wellness advantage team in evaluating all current resources and harmonizing the well-being efforts at Baptist Health South Florida.

\section{DECLARATION OF INTEREST}

The author reports no conflicts of interest. The author alone is responsible for the content and writing of the paper.

\section{AUTHOR}

Ana M. Viamonte Ros, MD, MPH

Medical Director Bioethics \& Palliative Care, Chief Well-Being Officer, Baptist Health Medical Group, Associate Professor for Women in Medicine, FIU Herbert Wertheim College of Medicine, Miami, FL, US. Correspondence regarding this paper can be directed at: AnaVR@,baptisthealth.net 